\title{
The Cognitive Science of Metaphor from Philosophy to Neuroscience
}

\begin{abstract}
In this paper I review some of the theoretical issues surrounding metaphor, and trace them through the context of the cognitive neuroscience debate. Metaphor, like all figurative language, has typically been explained as a secondary linguistic process which is a function taking place on literal language. However this explanation does not fit well with some of the recent work on right hemisphere processing of language or recent cognitive studies, both of which suggest that the figurative and literal language are processed simultaneously and share much substructure. In seeking ways to operationalize the Lakoff and Johnson view of conceptual metaphor as a constitutive cognitive phenomenon, I begin to spell out what kinds of theoretical predictions the Lakoff Johnson model would make on the neurophysiological levels af cognitive investigation. I conclude by offering some thoughts on new directions of research using these methods, and by reassessing the philosophical basis of these matters.
\end{abstract}

\section{Introduction and Theoretical Overview}

Whatever the skill employed in thought that of logic, mathematics, language, spatial or musical symbols - we must not forget that it is driven by the Jamesian processes, undergoes flights and perchings, is susceptible to great variations in attention, and in general, is fueled by metaphoric and metonymic processes.

(Gerald Edelman, Bright Air, Brilliant Fire, p. 174)

Though it has long been recognized that most of our everyday uses of language involve metaphor, with a few notable exceptions (such as Winner \& Garner, 1977) the enterprise of cognitive science has largely ignored the 
investigation of figurative language in favor of investigating literal language until recently. Of the many factors which contributed to the paucity of research on figurative language comprehension, the instantiation hypothesis is perhaps the most onerous. Proponents of the instantiation hypothesis argued that reason, intelligence and minds were substrate neutral, that is, independent of any specific embodiment, so long as the brain seen as the computational device which ran the algorithms collectively known as mind.

In the commonest manifestation of this misguided view, the computational device of choice was a serial processor driven digital computer. Since the mathematician Alan Turing had proved that all digital computers were in principle reducible to recursive elaboration of a finite state algorithm (a 'Turing machine'), minds (and mental 'processes ${ }^{1}$ ) were in principle reducible to finite state algorithms. Finite state algorithms have a peculiar literal quality in that their variables are discrete; they either in one state or another, just as linguistic propositions were supposed to be true or false with no admixture of truth or falsity permitted. Upon this view the fundamental problem of language comprehension was determining how the brain's representations and the world literally matched up: the world outside the brain was thought to be represented inside the brain by a series of discrete state symbols.

Now as the mind was considered to be that kind of software program running on that kind of hardware, the lack of attention given to figurative language comprehension followed from an obvious source. Figurative language comprehension was considered a mere afterthought to solving the problem of literal language comprehension because Turing had shown that all such computational processes must ultimately decompose into discrete states, and hence the mental processes of metaphoric comprehension must decompose into those of literal comprehension. The mantra of this dogma was clear: Solve first how language and mind symbolically represent the world as a series of discrete states and the problems posed by metaphoric and figurative language comprehension will inevitably solve themselves.

Unfortunately for proponents of the instantiation hypothesis, many of the recent findings in cognitive science are motivated by its antithesis: the embodiment hypothesis. The embodiment hypothesis argues that minds are fundamentally not disembodied algorithmic processes like those in a (serially-driven discrete state) digital computer program, but are instead constituted and constrained by the kinds of organization reflected in the biological, anatomical, biochemical, and neurophysiological characteristics of the body and the brain. While both hypotheses share the materialist assumption that higherlevel processes, such as abstract thought, language comprehension and the like, are built up out of lower-level processes, the embodiment hypothesis explicitly denies the substrate neutrality claim of the instantiation hypothesis proponents. Rather 
than processes which manipulate symbols in a finite-state fashion, the study of mind as a biological and neurophysiological enterprise requires thinking about the mind and brain using a series of interwoven levels of investigation, within many of which the embodied mind appears to compute using analog rather than discrete states circuitry, processes and passes forward information which is analogous to prior information and frequently exhibits a kind of adaptive plasticity not found in digital computers.

In order to bring the embodied mind back into the foreground, a good cognitive theory requires a kind of vertical convergence across a number of different levels of investigation ranging from philosophy, linguistics, anthropology through developmental, cognitive psychology, neuropsychology and neurology and down to neuroanatomy and neurochemistry. In the rest of this paper I will be arguing for the utility of such a broadbased framework for researching mind. As an example I will be reviewing much of the current research on figurative language processing and metaphor in several of these fields, but I should be quite to point out that I could equally as well have chosen topics such as differing spatial frames of reference, or alternatively the imagination and mental imagery, in order to set out this theoretic framework. However, as I have already made clear, metaphor and other kinds of figurative language are especially important topic to study using this theoretic framework. The reason is that the recent work on metaphor and figurative language overturns some of our mostly deeply held (yet misguided) beliefs about the way that language and minds work. By considering this particular topic area we can see the ways in which the old system of discretestate computer models and literal language as a matter of symbolic representation no longer hangs together as a unified coherent whole given contemporary neuroscience, while by contrast the new view of language as constitutively metaphoric, neural network modeling, and contemporary neuroscience do hang together in a coherent theoretic framework.

Figurative language comprehension has robust connections with the embodiment hypothesis, especially in the area of metaphor. As George Lakoff (1987) and Mark Johnson (1987) have argued, our ordinary use of language is largely structured by metaphoric and metonymic principles which exhibit a directionality from bodily sources to abstract targets. Human beings systematically characterize more abstract ideasthoughts, religious beliefs, political and ethical situations-in terms of bodily domains (such as spatial movements and bodily functions). The primary claim of their position is that these metaphors and the directionality are not arbitrary, but instead are a natural outgrowth of the manner in which our minds and brains are constituted.

In particular, humans regularly project image schematic patterns of reasoning $\mathrm{i}$ Johnson, 1987) from one domain to another. These image schemata are recurrent crossmodal patterns which comprise the meaningful structures of our experience, 
primarily in perceptual domains such as bodily movement and vision. For example, humans have a contaiment image schema which results from our regular recurring experiences of putting objects into and taking them out of a bounded area. We can experience this pattern in the kinesthetic modality with physical containers, or we can experience this pattern visually as we track the movement of some object into or out of some bounded area or container. These patterns can then be metaphorically extended to structure non-physical, non-tactile and non-visual experiences. In a particularly striking set of examples, Johnson traced many habitual notions of containment we might experience during the course of a typical morning routine: We wake up out of a deep sleep, drag ourselves up out of bed and into the bathroom, where we look into the mirror and pull a comb out from inside the cabinet. Later that same morning we might wander into the kitchen, sit in a chair at the breakfast table and open up the newspaper and become lost in an article. Some of these experiences are spatial and physical but do not involve the prototypical containment image schema (as in the example of sitting in a chair) while some of these experiences draw on purely metaphorical extensions of containment (as in the example of getting lost in the newspaper article).

Working from considerable linguistic evidence, Lakoff and Johnson argued that such metaphors exhibit a stable uniformity of direction in which we metaphorically project the more bodily-based perceptual patterns to understand more abstract domains. As such, their original formulation of the role of embodiment to cognitive science was primarily concerned with the directionality of metaphoric projection in their linguistic evidence, but has rapidly grown to take in evidence from other sciences. Hypotheses such as these lend themselves to a multileveled approach, and in this paper I explicitly tie together threads from the philosophical, cognitive, and neurophysiological levels of investigation; a fuller exposition will of course consider more levels of investigation. I now turn to developing explicitly the theoretic framework of the embodiment hypothesis.

\section{The levels of investigation theoretic framework}

As an initial step in operationalizing the Lakoff Johnson hypotheses about embodiment and conceptual metaphor I have made use of Posner and Raichle's (1994) schematization of the levels of cognitive science (Figure 1) as a framework. The most basic organizing criterion of my theoretic framework is the scale of the relative physical sizes of the phenomena which produce the different kinds of cognitive or neural events to be studied.

Size is mapped on the y-axis, providing a relative distribution of the "higher to lower" levels of cognitive processes. To provide clarification I provide examples of what the relevant physiological structures are in the next column, where I 
detail a secondary organizing criterion by identifying some of the most relevant physiological structures at a given physical scale. I then describe the "Level of Investigation" in accordance with the kinds of cognitive processes studied at that order of magnitude. The general name of each level is indicated by bold type.

Because I want to preserve Posner and Raichle's deep insight that it is profitable to consider how the experimental tasks change at various levels of investigation, the "Tasks" column of this theoretic framework specifies for conceptual metaphor theory in particular some typical relevant experimental tasks. Where the notion of an experimental task does not apply, I provide some other relevant foci of analysis. In the next column I describe some of the relevant theoretical constructs operative at the level of investigation, while in the final column I identify some of the various methods used to study phenomena at that level of investigation.

\begin{tabular}{|c|c|c|c|c|c|}
\hline Size & $\begin{array}{l}\text { Physiological } \\
\text { Structures }\end{array}$ & $\begin{array}{c}\text { Level } \\
\text { of Investigation }\end{array}$ & $\begin{array}{c}\text { Typical } \\
\text { Conceptual } \\
\text { Metaphor Theory } \\
\text { Tasks }\end{array}$ & $\begin{array}{l}\text { Sample } \\
\text { Operative } \\
\text { Theoretical } \\
\text { Constructs }\end{array}$ & $\begin{array}{l}\text { Sample } \\
\text { Methods of } \\
\text { Study }\end{array}$ \\
\hline 1 & 2 & 3 & 4 & 5 & 6 \\
\hline $\begin{array}{l}1 \mathrm{~m} \text { and } \\
\text { up }\end{array}$ & $\begin{array}{l}\text { Multiple } \\
\text { Central } \\
\text { Nervous } \\
\text { Systems }\end{array}$ & \begin{tabular}{|l} 
Cognitive and \\
conceptual \\
systems in culture, \\
history, language, \\
science, rhetoric, \\
literature, and \\
philosophy
\end{tabular} & $\begin{array}{l}\text { Use of widespread } \\
\text { cultural metaphors } \\
\text { and novel poetic } \\
\text { metaphors in } \\
\text { interpersonal } \\
\text { communication; } \\
\text { historical and } \\
\text { cross-cultural } \\
\text { analyses of } \\
\text { conceptual me- } \\
\text { taphors }\end{array}$ & $\begin{array}{l}\text { Complex } \\
\text { conceptual } \\
\text { metaphor, } \\
\text { conceptual } \\
\text { blends, } \\
\text { disanalogy }\end{array}$ & $\begin{array}{l}\text { Linguistic } \\
\text { analysis, textual } \\
\text { analysis, discourse } \\
\text { analysis, } \\
\text { phenomenological } \\
\text { philosophical } \\
\text { analysis }\end{array}$ \\
\hline $\begin{array}{l}.5 \mathrm{~m} \text { to } 2 \\
\mathrm{~m}\end{array}$ & $\begin{array}{l}\text { Central } \\
\text { Nervous } \\
\text { Systems }\end{array}$ & $\begin{array}{l}\text { Performance } \\
\text { domain; } \\
\text { Cognitive, } \\
\text { conceptual and } \\
\text { linguistic systems } \\
\text { as performed by } \\
\text { individual } \\
\text { subjects }\end{array}$ & $\begin{array}{l}\text { Understanding } \\
\text { metaphors (both } \\
\text { conventional \& } \\
\text { unconventional), } \\
\text { extending } \\
\text { metaphoric } \\
\text { inferences to } \\
\text { novel, } \\
\text { facilitation of } \\
\text { related } \\
\text { information, } \\
\text { inference } \\
\text { generalizations }\end{array}$ & $\begin{array}{l}\text { Complex con- } \\
\text { ceptual metaphor, } \\
\text { conceptual blends, } \\
\text { disanalogy, } \\
\text { primary or } \\
\text { orientational } \\
\text { metaphor, } \\
\text { mappings, } \\
\text { inference } \\
\text { generalizations }\end{array}$ & $\begin{array}{l}\text { Verbal report, } \\
\text { observational } \\
\text { neurology and } \\
\text { psychiatry, } \\
\text { discourse } \\
\text { analysis, } \\
\text { metaphor } \\
\text { cognitive and } \\
\text { developmental } \\
\text { studies } \\
\text { examining } \\
\text { reaction time } \\
\text { (RT) }\end{array}$ \\
\hline
\end{tabular}




\begin{tabular}{|c|c|c|c|c|c|}
\hline 1 & 2 & 3 & 4 & 5 & 6 \\
\hline $\begin{array}{l}10^{1} \mathrm{~m} \text { to } \\
10^{\prime 2} \mathrm{~m}\end{array}$ & $\begin{array}{l}\text { Gross to medium } \\
\text { size neural regions } \\
\text { anterior cingulate, } \\
\text { parietal lobe, etc.) }\end{array}$ & Neural systems & $\begin{array}{l}\text { Activation course } \\
\text { in somatosensory, } \\
\text { auditory, and } \\
\text { visual processing } \\
\text { areas when } \\
\text { processing } \\
\text { conceptual } \\
\text { metaphor or } \\
\text { multimodal } \\
\text { perceptual } \\
\text { experiences }\end{array}$ & $\begin{array}{l}\text { Conceptual } \\
\text { mappings,prim } \\
\text { ary metaphor, } \\
\text { conceptual } \\
\text { blends, } \\
\text { disanalogy, } \\
\text { image } \\
\text { schemata, } \\
\text { topographic } \\
\text { maps }\end{array}$ & $\begin{array}{l}\text { Lesion analysis, } \\
\text { neuroimaging with } \\
\text { fMRl, } \\
\text { PET sometimes in } \\
\text { combination with } \\
\text { ERP, neurological } \\
\text { dissociations, } \\
\text { neuro- } \\
\text { computational } \\
\text { simulations }\end{array}$ \\
\hline $\begin{array}{l}10^{\prime 2} \mathrm{~m} \text { to } \\
\mathrm{IO}^{-4} \mathrm{~m}\end{array}$ & $\begin{array}{l}\text { Neural } \\
\text { networks, maps } \\
\text { and pathways }\end{array}$ & $\begin{array}{l}\text { Neuroanatomy; } \\
\text { Neural circuitry in } \\
\text { maps, pathways, } \\
\text { sheets }\end{array}$ & $\begin{array}{l}\text { Neuro- anatomical } \\
\text { connections from } \\
\text { visual, auditory, } \\
\text { somatosensory } \\
\text { region to language } \\
\text { areas }\end{array}$ & $\begin{array}{l}\text { Image } \\
\text { schemata, } \\
\text { primary } \\
\text { metaphor, } \\
\text { topographic } \\
\text { maps, } \\
\text { convergence } \\
\text { zones } \\
\end{array}$ & $\begin{array}{l}\text { Electrocellular } \\
\text { recording, ana- } \\
\text { tomical dyes \& } \\
\text { other methods, } \\
\text { neurocomputa- } \\
\text { tional } \\
\text { simulations }\end{array}$ \\
\hline $\begin{array}{l}10^{\prime 3} \mathrm{~m} \text { to } \\
10^{\prime 5} \mathrm{~m}\end{array}$ & $\begin{array}{l}\text { Neurons, } \\
\text { Cortical } \\
\text { columns }\end{array}$ & $\begin{array}{l}\text { Neurocellular } \\
\text { systems; } \\
\text { Cellular and very } \\
\text { small intercellular } \\
\text { structures }\end{array}$ & $\begin{array}{l}\text { Neuroanatomy of } \\
\text { particular } \\
\text { structures } \\
\text { recruited by } \\
\text { image schemata } \\
\text { and conceptual } \\
\text { metaphor }\end{array}$ & Pyramidal cells & $\begin{array}{l}\text { Electrocellular } \\
\text { recording, ana- } \\
\text { tomical dyes \& } \\
\text { other methods, } \\
\text { neurocomputa- } \\
\text { tional } \\
\text { simulations }\end{array}$ \\
\hline $\begin{array}{l}\text { Less } \\
\text { than } \\
10^{65} \mathrm{~m}\end{array}$ & $\begin{array}{l}\text { Neuro-transmit- } \\
\text { ters, ion channels, } \\
\text { synapses }\end{array}$ & $\begin{array}{l}\text { Subcellular } \\
\text { systems; } \\
\text { subcellular, } \\
\text { molecular and } \\
\text { electrophysical }\end{array}$ & $\begin{array}{l}\text { None-beyond } \\
\text { theoretical } \\
\text { scope }\end{array}$ & $\begin{array}{l}\text { Neurotrans } \\
\text { mitter }\end{array}$ & $\begin{array}{l}\text { Neuro-phar } \\
\text { macology, } \\
\text { neurochemistry. } \\
\text { neurophysics }\end{array}$ \\
\hline
\end{tabular}

Figure 1. Theoretic Framework for the Embodiment Hypothesis in Cognitive Science as Applied to Conceptual Metaphor Theory

No concise sketch of a theoretic framework can represent everything important adequately well at every point, and I want to outline two quick caveats about my presentation of the theoretic framework. In particular, I have included at the top level a special place for what is a vast and all too often underemphasized level of research in cognitive science; that of human beings in interaction with one another and with the artifacts of the environment they create. While accurate in terms of the physical scale at which the interactions largely take place, my designation of the physiological organization here as "multiple central nervous 
systems" is perhaps a little coarse. What I mean by including this level of analysis is to emphasize not simply people in interaction with one another in intellectual and other problemsolving situations, but also their interaction with the devices and artifacts which aid in our cognition. For example, with respect to navigation systems employed by both Western and non-Western seafarers Hutchins (1995) has done a marvelous analysis of the how differing kinds of artifacts (sextants, sidereal box compasses, etc.) constitute a level of cognition that is socially and culturally transmitted in the expert uses of such devices.

Secondly, it is highly important to mention that giving a theory of the embodied mind requires acknowledging that we are dealing with an entities which develop, change, degrade and evolve across time. Time has two particularly important dimensions not well illustrated by this presentation of the theoretic framework. First, there is an ontogenetic dimension in which we must consider that all levels of investigation in this chart are subject to study from the vantage of human development from infancy to adulthood. There are also further considerations involving the gradual degradation of cognitive systems as adults age, and yet more temporal issues about the extent to which cognitive functions can be recovered in cases of traumatic brain injury. A second important axis of temporal consideration is the phylogenetic dimension. Human beings evolved their more speciesspecific capabilities of speaking, imagining and planning from previously evolved capacities, and studies of the cognition of our primate cousins, the fossil records of our ancestors and our genetic histories may reveal a great deal about the order and organization of our "higher" cognitive processes.

\section{Literature review: philosophical work and cognitive systems research}

Most philosophers have generally argued that figurative language involves tricks or plays on the literal. John Searle (1979), for example, argued that metaphor is a simply a roundabout way to express literal semantics. I have schematized Searle's view of metaphor in Figure 2. According to Searle's model, all utterances would be processed as literal utterances first. Only once the mind was unable to find a literal meaning for an expression would the utterance be sent to a special non-literal processing center for decoding. Searle's view necessarily entails that the comprehension of a metaphor assumes the metaphoric expression will eventually be decomposed into a literal paraphrase.

On the face of it Searle's model appears to have significant naive appeal, for it fits with our common sense experience of understanding language and speech. However that common sense understanding fundamentally confounds the distinction between literal and figurative speech with another distinction: that between attended and automatic processes. In our common sense understanding we think of 
metaphors as unusual utterances which require our attention, such as we encounter in poetry or theater. We think of a metaphor as something jarring which interrupts our ordinary way of thinking about the world and challenges us to enter into another way of thinking. Given Searle's commonsensical definition of metaphor, literal language comprehension would be accomplished automatically while the comprehension of metaphoric language would require attended processing.
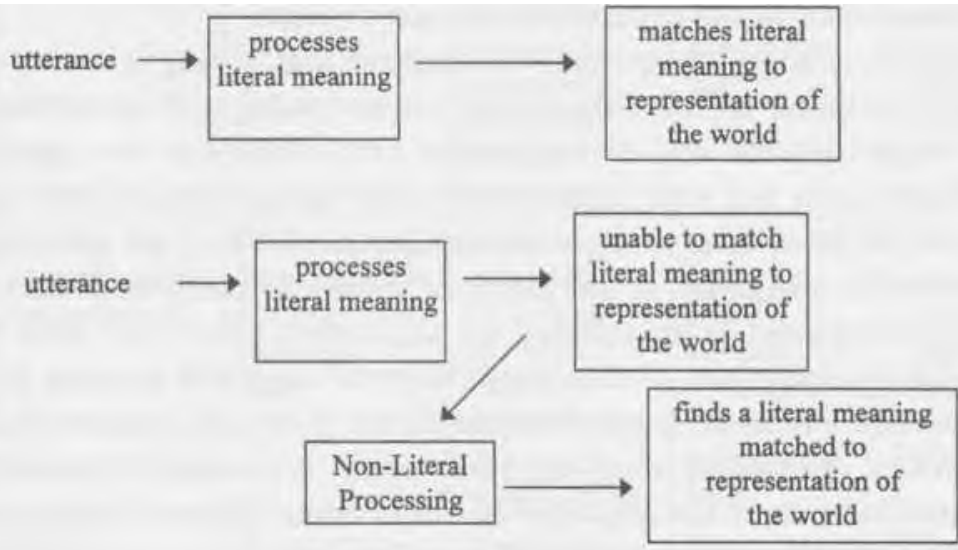

Figure 2. A schematization of Searle's sequential model (1979) of metaphor comprehension

However, Lakoff and Johnson have shown that much of our everyday language, including much of what we would ordinarily call literal language, is structured by conventional conceptual metaphors. The key realization was seeing that metaphoric expressions are not simply isolated acts of creative expression, but are instead are systematic in projecting the knowledge from one domain of experience onto another. For example, in the creative metaphoric expression taken from an American pop song "It was love in the fast lane" is perfectly intelligible because it extends the entrenched cultural metaphor Love is a journey. American English speakers regularly talk about love affairs with expressions such as "our relationship has hit a dead-end street", "he and I just ran out of gas", "we're sailing along right now", and that systematicity is the conceptual connectivity that serves to make the creative metaphor expression intelligible. (For further evidence see Lakoff and Johnson 1980; Turner 1989).

In other words, what Lakoff and Johnson showed was that the bulk of our metaphoric processing is automatic-it is only some metaphors require attended processing. Couple their observations with the fact that some forms of language which we would ordinarily consider literal (such as scientific reports) also require attended processing even though most forms of literal language (such as social interactions, reading a newspaper and the like) are also processed fairly 
automatically, and the luster of Searle's model of how we understand metaphor begins to fade. These considerations suggest two additional kinds of theoretical models: a second model in which both literal and metaphoric processing are done in parallel; and a third in which both literal and metaphoric processes are largely the same process.

A number of cognitive methods can be applied to help adjudicate between these three theoretical models. As Searle's model is a sequential hypothesis, it requires that a metaphoric utterance first be processed as if it were literal, judged non-literal and then alternate strategies are employed to decode the utterance into literal. Presumably all these actions take place in real time, which would imply that metaphoric utterances take longer to understand than literal utterances.

However, many studies of figurative language - on idioms, proverbs and metaphor show that this is not the case (see Gibbs 1994, pp. 92-108 for a useful overview), provided there is sufficient context. Ortony, Schallert, Reynolds \& Antos (1978) measured the time it took subjects to comprehend literal v. metaphoric sentences at the end of long and short contexts, and reported that while there was no difference for long contexts, metaphoric sentences took significantly longer to read in short contexts. Similarly, Janus \& Bever (1985) tracked eye movements and compared the amount of time people focused on the target sentences. Subjects again responded more quickly in the long context condition. These results contraindicate the Searlean sequential model of metaphor processing; additionally, the possibility that metaphoric contexts are 'chunked' and processed as semantic units is contraindicated by the differing results in the long v. short context conditions. (Presumably if metaphors were chunked in a fashion similar to lexemes they would have been retrieved in nearly equal times for either the short or long context conditions - this was clearly not the case). Finally, it should be noted as a caveat that other studies (Blasko \& Connine, 1993) show that highly familiar metaphors are understood more quickly than novel metaphors - in other words, these processing time studies must be taken cautiously as they show practice effects.

While these type of cognitive studies adequately contraindicate the Searlean model of metaphoric processing, they have not yet proved as revealing in determining whether literal and figurative language processing are parallel processes or are largely the same process. With respect to idiomatic language Gibbs $(1980,1986)$ has shown that subjects take less time to read idiomatic phrases when the context supports an idiomatic interpretation than the same phrases in contexts supporting a literal interpretation. The differing results with respect to context suggest that the literal and figurative language comprehension processes operate in parallel and the context primes one process or the other. Similar results have been obtained with regard to metaphor (summarized in Gibbs, 1994, p. 101-4). Yet subjects seem unable to ignore a figurative meaning even when instructed to focus exclusively on the literal context (Keysar, 1989). Keysar 
investigated whether metaphor and literal interpretations of a context would produce a Stroop-like interference effect when a target was, for example, both metaphorically true and literally false. Reaction times increased in the invalid condition but decreased in the valid condition, suggesting that these processes may well at least share component subsystems. Ultimately cognitive methods alone may not be able to decisively resolve the parallel and same process debate because that question may be better posed at other levels of investigation than the cognitive systems level.

Finally, there has been an interesting exchange between the Lakoff Johnson- Gibbs approach and the largely complementary Glucksberg-Keysar-McGlone approach. Along with Lakoff and Johnson, Gibbs (1992) claims that long-term memory is structurally organized by prototypes extended by metaphoric and metonymic principles called conceptual metaphors or conceptual mappings. A conceptual metaphor, such as Love is a journey, is constituted by mappings between areas of the brain, such as from affect and sensorimotor areas to semantic areas. In the appropriate context, most conventional metaphoric expressions, such as we're at a crossroads or our marriage is on the rocks, access these conceptual metaphors from long-term memory. Glucksberg, Keysar and McGlone (1990) argue for a class inclusion view in which some metaphoric expressions build up an ad-hoc category in working memory rather than accessing conceptual metaphors from long-term memory, even when it would be expected that they would draw on a conceptual metaphor. Gibbs $(1992,1994)$ argues that the class- inclusion view requires an understanding of metaphor in which each metaphoric expression creates a unique or novel mapping in working memory. In their reply Glucksberg, Keysar and McGlone (1992) suggest that only some cases require the development of an ad-hoc category, citing a brief initial experiment in which subjects were given metaphoric expressions with minimal context and asked to paraphrase them.

\section{Literature review: neurophysiological investigations of metaphor}

Some of the strongest evidence against a purely parallel processing model for figurative and literal language comprehension comes from a number of studies on right hemispheredamaged (RHD) patient populations. One possible localization of these parallel processes would suggest that they could be lateralized with respect to brain hemispheres. In an early study often cited as establishing that metaphoric processing is right hemisphere dependent, Winner \& Gardner (1977) compared left hemisphere-damaged (LHD) aphasic patients, RHD patients, bilaterally damaged patients and a non-neurological group. Participants were presented with a figurative sentence such as "he has a heavy heart" and asked to 
perform two tasks. One task involved matching the sentence to one of four pictures, one of which literally represented the sentence (i.e., a man carrying a large heart), an appropriate metaphoric interpretation (a crying man), a salient quality depicted by the metaphoric adjective (a $500 \mathrm{lb}$ weight) and one which illustrated the noun (a large heart). In the second task patients were asked to verbally explain their choices. While RHD patients selected the metaphoric picture much less frequently than LHD patients or the control group in the first task, in the second task RHD patients were able to verbalize their choices using figurative language whereas LHD patients were unable to explain their 'correct' choices verbally.

Winner \& Gardner argue that these results show that the effective interaction of the hemispheres was important in appreciating figurative meaning. Though this study clearly shows that the figurative and literal language comprehension processes are not parallel processes in differing hemispheres, the study also indicates that at least some subcomponents of language comprehension concerned with metaphoric processing are RH dependent. In short, the $\mathrm{RH}$ makes a positive contribution to figurative language processing. This kind of lesion evidence further suggests that debate over the serial/parallel processing of literal and figurative language comprehension is too crude a theoretic tool to be useful in determining the localization of semantic processing, suggesting instead that the figurative and literal language processing share at least some but not all subcomponents.

This conclusion was underscored in a related study by Brownell et al. (1990) which also showed that RHD patients were more impaired in pairing a word with a metaphoric synonym than LHD patients. In addition to providing further support for the idea that the right hemisphere makes a unique contribution to figurative language processing, they also report that LHD patients were affected by the degree of semantic similarity between the target and its synonym in the metaphoric - but not the literal-condition. This finding is intriguing because it suggests that the right and left hemispheres may code semantic information in different ways. Work on RH contributions to semantic priming (summarized in Beeman et al. 1993) generally suggests that semantic memory is either stored differently in the RH or processed differently in the RH. Beeman argues for the latter, suggesting that the $\mathrm{RH}$ and $\mathrm{LH}$ do operate in parallel with respect to semantic processing, with the $\mathrm{RH}$ processing the information in a coarser fashion and the LH in a fine fashion. The coarse-fine distinction is drawn from neural network modeling of vision which suggests that networks which use larger receptive fields code information more coarsely, thereby maximizing responsivity to precisely localizing a source of continuous input. According to this hypothesis the coarser semantic fields of the RH would operate in parallel with the more finely grained semantic fields of the left hemisphere. Figurative language comprehension would then entail a RH activation strong enough to influence LH hemisphere processing. 
If Beeman's theory can be adapted to understanding the phenomenon of conceptual metaphor, the context effect observed in the cognitive studies would presumably be instantiated as a build-up of strong patterns of activation in the RH. This explanation is also consonant with the Stroop-like interference effect that Keysar ( 1989) noted in which the availability of metaphoric interpretations slowed the RT of literal interpretations. By positing a shared semantic network which differs only in the scope and weighting of the neural nets, this theoretical model nicely captures both the shared componentry evidenced by the interference between literal and figurative processing and the parallel processing suggested by the decreased reaction times in the long context condition. Rather than architecturally separate modules for literal and figurative processing, this theoretical model posits a literal-metaphorical continuum instantiated by varying the weighting of neural networks.

The conceptual metaphor model, however, seems to argue against a strict localization of metaphoric processing as a shared semantic network primarily lateralized in the RH. Instead the idea that image schematic patterns of reasoning are projected from perceptual modalities in more abstract conversation leads to the prediction that there should be activation in related sensorimotor areas during metaphoric processing (i.e. visual metaphors should activate visual/imagery areas, tactile metaphors should activate tactile areas, etc.). This may or may not prove to be a significant incompatibility with Beeman's hypothesis, and I discuss some proposals for teasing apart the issue in the following section.

\section{Proposals for current research}

There remain, however, unanswered questions about the role of conceptual metaphors as largely automatic (unattended) processes in the brain. Lakoff (1991) argues that "the system of conventional conceptual metaphor is mostly unconscious, automatic and available to users with no noticeable effort". If conceptual metaphors are largely automatic and if metaphoric processing is largely instantiated by coarse semantic fields in the RH, the RH should show a strong and growing activation pattern in the long context condition of the cognitive studies on metaphor. This hypothesis could be investigated using fMRI methodology by reproducing the cognitive studies on metaphor and rather than measuring the RT needed to comprehend a sentence, looking instead for a growing pattern of activation in the RH. Imaging techniques could compare early, middle and late activations involved in the comprehension of the passage. The appropriate subtractions would be the event images minus an image of the subject at rest (either reading nonsense text or 'literal' text). Presumably these subtractions would show greater RH activation late in the passage. If ERPs were used in conjunction 
with a neuroimaging method, a clearer picture of the time course might provide us with insight about the rate of the expected build-up in the $\mathrm{RH}$.

Another line of inquiry to investigate would focus on the notion of a conceptual metaphor. The conceptual metaphor hypothesis proposes that there will be interconnections between semantic areas and areas tightly related to sensory input. A passage which uses visual metaphors, for example, should activate pathways connected to the visual system and to some degree the areas themselves. A fMRI study could be designed which checked for activation in the visual, auditory, somatosensory and motor cortices after reading or hearing a passage with strong visual, auditory, tactile or bodily movement metaphors. The relevant subtraction would change in each modality, but the basic approach would be to compare a loaded condition minus an unloaded condition; for example, for the visual modality an image after hearing a passage with visual metaphors minus an image of passive listening to a visual metaphor neutral text. One would expect to see activation in the visual/imagery areas of the brain. If there was no such activation, it would be substantial evidence contraindicating the conceptual metaphor view. However, all of these suggestions are subject to the caveat that the activation should be of large enough scale to be picked up by the resolution of the neuroimaging technique. On the neuroanatomical level of investigation, I would also expect that pathways should be observable between associated areas.

Another pressing need is to develop neuropsychological tasks to test for the presence of image schemata in both linguistic and non-linguistic contexts, so that investigation at the neural systems level can link areas known to have image schematic structure to language areas. With respect to the study of patient populations in neurological care, such research proceeds by examining the regions in which brain lesions lie that produce deficits of function. The ideal sorts of neuropsychological tasks are ones which doubly "dissociate" a behavior from a neural system-in other words, the behavior is present when system $\mathrm{X}$ is damaged and when system $\mathrm{Y}$ is intact, and it is not present when system $\mathrm{X}$ is intact and system $\mathrm{Y}$ is damaged. In order to be successful, such tasks must be highly specific and often test the conceptions of a higher level of investigation (such as conceptual metaphors) on a piecemeal basis. Once a well-designed task sufficiently establishes a dissociation in patient populations, it can usually be adapted to the physical and temporal constraints of neuroimaging experiments. Some of the constraints on such experiments include (1) finite windows of time in which the activation can be measured; (2) the activation patterns must be relatively stable; (3) the task should be repeatable within the time window.

What kinds of deficits in neurological function might one expect to observe, if image schemata do in fact underlie the conceptual metaphors which make up much of our linguistic and conceptual systems? This is not an easy question to answer. A plausible start might go as follows. A long tradition of neurological 
research (summarized in Caramazza 1996) on conceptual categorization has shown that patients have selective deficits for tools as opposed to persons or animals, and more recent neuroimaging studies suggest there may be an association between the embodied patterns of hand movements and the ability to recall words for hand tools (Damasio et al. 1996). Working along similar lines we might analogously extend this work to investigate conceptual metaphor. As Gibbs' reaction-time studies in psychology argue that conceptual metaphors facilitate related inferences, then it may be possible that such patients would show deficits in their ability to draw inferences based on conceptual metaphors where tool use or particular animals serve as part of the source domain. Presumably the facilitation effects which Gibbs' work observes in healthy patients would not be found.

Similarly, investigating image schemata might show even more selective deficits, if some patients fail to respond to a facilitation cue for a particular kind of conceptual mapping. For example, the containment schema underlies numerous mappings in different conceptual metaphors, from deeply conventionalized mappings such as getting lost in the newspaper to highly inventive and difficult ones such as occur in thinkers such as Plato. One could test a patient with a battery of metaphoric expressions which draw on the containment image schema, and develop other sets of metaphors which try to isolate the other image schemata. If the hypothesis bears out and selective deficits were observed to knock out particular kinds of image schematic structure, then lesion analysis using neuroimaging techniques might then even show a localization of function for differing image schemata.

\section{Conclusion}

The study of metaphor (and figurative language processing generally) affords us with an excellent opportunity to reassess the philosophical basis of cognitive science. Previous generations of cognitive science were laden with poor assumptions derived from AngloAmerican approaches in the philosophies of mind, logic, and language. In recap, these were (i) that minds were disembodied symbol processors indifferent to the details of their embodiment (i.e., substrate neutral); (ii) that language, as modeled on symbolic logic, was first a matter of literal reference and only secondarily a matter of figurative construal; (iii) that metaphors and other figurative language were isolated acts of the creative imagination, and therefore matters of attended-as opposed to automatic or unconsciousprocessing. In another context I might be tempted to explore the philosophical origins of this mistaken view at the beginnings of the $20^{\text {th }}$ century, which have some roots in Frege's theory of multiple senses which can refer to 
the same object and the early Wittgenstein and Russell's dream of a perfect language into which all the world's languages might be translatable (and thus instrumental in avoiding the misunderstandings which Russell believed led people to war), but those are merely speculative thoughts in this present context.

What I have provided instead is an example of tackling a problem through an alternative philosophical framework known as the embodiment hypothesis. I have primarily opposed my notion of embodiment to the Anglo-American tradition's conception of substrate neutrality, but I have also fleshed it out by providing a multileveled theoretic framework within which cognitive processes like metaphor can be evaluated. Such an approach draws on many interrelated disciplines which take up relatively similar lines of inquiry (given their methodological constraints). In the next century, the study of mind and language ••ill change dramatically. The methodologies which are now coming on-line to peer into the brain in real time are one important component of that revolution, but equally important is the sea change in the conception of cognition.

Whereas previously cognition was considered to be primarily symbolic manipulation taking place only in the head, we are now asking about the roles played by the body and the environmental situation in cognition. This new approach to cognition is far more interactional and pragmatic than the former approach, and cognitive scientists are now far more willing to admit that we rumans use multiple different cognitive construals rather than reducing cognition to a single kind of processing. In the process we are making a sea change from a philosophical conception of cognition as centered about a universal machine, usually a digital computer (see Newell and Simon's 1990 formulation of their Physical Symbol System [PSS] hypothesis) to one centered about problems and patients. The real philosophical change is from a PSS-centered cognitive science philosophy to a PCP (patient and problem solving-centered philosophy) of cognitive science, and the study of metaphor is in the vanguard.

\section{References}

Beeman, Mark et al. (1993). "Summation priming and coarse semantic coding in the right hemisphere". Journal of Cognitive Neuroscience, 6, 26^15.

B asko, D., \& Connine, C. (1993). "Effects of familiarity and aptness on metaphor processing". Journal of Experimental Psychology: Learning Memory, and Cognition, 19, 295-308.

Brownell, Hiram H. et al. (1990). "Appreciation of metaphoric alternative word meanings by left and right brain-damaged patients". Neuropsychologia, 28, 375-383.

haramazza, Alfonso. (1996). "The Brain's Dictionary.” Nature, v. 380, 11 April, pp. 485-86. Damasio, Hanna, et al. (1996). “A Neural Basis for Lexical Retrieval.” Nature, v. 380,

11 April, pp. 499-505. 
Edelman, Gerald M. (1992). Bright Air, Brilliant Fire: on the matter of mind. New York: Basic books.

Gibbs, Raymond. (1980). "Spilling the beans on understanding and memory for idioms in conversation." Memory \& Cognition, 8, 449-456.

Gibbs, Raymond. ( 1986). "Skating on thin ice: literal meaning and understanding idioms in conversation." Discourse Processes, 9, 17-30.

Gibbs, Raymond. (1992). "Categorization and Metaphor Understanding." Psychological Review, 99, 572-577.

Gibbs, Raymond. (1994). The Poetics of Mind: Figurative Thought, Language and Understanding. Cambridge, Eng.: Cambridge University Press.

Glucksberg, Sam, B. Keysar and M. McGlone. (1990). "Metaphor understanding and accessing conceptual schema: Reply to Gibbs (1992)”. Psychological Review, 99, 578-581.

Hutchins, Edwin. (1995). Cognition in the Wild. Cambidge, MA: MIT Press.

Janus, R., \& Bever, T. (1985). "Processing metaphoric language: An investigation of the three stage model of metaphor comprehension." Journal of Psycholinguistic Reseach, 14, 473-487.

Johnson, Mark. (1987). The Body in the Mind: The Bodily Basis of Meaning, Imagination and Reason. Chicago: University of Chicago Press.

Keysar, Boaz. (1989). "On the functional equivalence of literal and metaphorical interpretations in discourse". Journal ofMemory and Language, 28, 375-385. Lakoff, George. (1987). Women, Fire and Dangerous Things. Chicago: University of Chicago Press.

Lakoff, George. (1991). “The Contemporary Theory of Metaphor.” In Ortony, Andrew (ed.) Metaphor and Thought, 2nd. ed. New York: Cambridge University Press.

Lakoff, George and M. Johnson (1980). Metaphors We Live By. Chicago: University of Chicago Press.

Newell A. and Simon, H. A. 1990. "Computer Science as Empirical Inquiry: Symbols and search.” In J. L. Garfield (ed.), Foundations of Cognitive Science: The Essential Readings, Paragon House.

Ortony, Andrew, D. Schallert, R. Reynolds and S. Antos. (1978). "Interpreting Metaphors and Idioms: Some effects of context on comprehension." Journal of Verbal Learning and Verbal Behavior, 17, 465-477.

Michael Posner and M. Raichle. (1994). Images of Mind. New York: Scientific American. Rohrer, Tim. (1998). "When Metaphors Bewitch, Analogies Illustrate and Logic Fails:

Controversies over the use of metaphoric reasoning in philosophy and science." $\mathrm{Ph}$. D.

Dissertation. Ann Arbor, Michigan: University Microfilms International.

Searle, John. (1979). “Metaphor.” In Ortony, Andrew (ed.) Metaphor and Thought. New York: Cambridge University Press.

Turner, Mark. (1989). Reading Minds. New Jersey: Princeton University Press.

Winner, Ellen \& Gardner, H. (1977). "The Comprehension of Metaphor in Braindamaged Patients." Brain, 100, 717-729. 